\title{
NAVIGASI KARAKTER 3D PADA GAME SHOOTER DENGAN MENGGUNAKAN VOICE COMMAND BERBASIS ANDROID
}

\author{
Much Miftachur Rohman ${ }^{1}$, Maulana Rizqi ${ }^{2}$ \\ ${ }^{1,2}$ Program Studi Sistem Komputer, Fakultas Ilmu Komputer, Universitas Narotama Surabaya \\ ${ }^{1}$ miftaweasley@gmail.com, ${ }^{2}$ maulana.rizqi@narotama.ac.id
}

\begin{abstract}
Abstrak
First Player Shooter merupakan permainan sebuah permainan yang menunjukan konten kekerasan tinggi,dimana terdapat aksi tembak menembak,memukul dan juga menusuk orang,tergantung cerita dan tokoh didalam permainan tersebut. Pada permainan ini dibagi menjadi 2 mode yaitu TPS ( Third-Person Shooter ) dan FPS (First-Person Shooter).perbedaannya ada pada view kita dalam bermain, dimana TPS memperlihatkan karakter yang sedang kita jalankan sedangkan FPS hanya memperlihatkan sebagian karakter yang sedang kita jalankan ( biasanya hanya memperlihatkan tangan ). Pada kali ini,penulis ingin membuat sebuah kombinasi permainan FPS dengan menggunakan Speech Recognition sebagai kontrol karakter utama. Speech Recognition sendiri merupakan sebuah Teknik yang memungkinkan perangkat untuk mengenali dan memahami suara yang kita hasilkan.
\end{abstract}

Kata kunci: Permainan FPS, Speech Recognition

\section{D CHARACTER NAVIGATION IN THE SHOOTER GAME USING ANDROID BASED VOICE COMMANDS}

\begin{abstract}
First Player Shooter is a game that shows high violence content, where there are shooting, hitting and stabbing people, depending on the story and character in the game. In this game divided into 2 modes namely TPS (Third-Person Shooter) and FPS (First-Person Shooter). The difference is in our view when playing, where TPS shows the character that we are running while FPS only shows some of the characters we are running (usually only showing hands). At this time, the writer wants to make a combination of FPS games using Speech Recognition as the main character control. Speech Recognition itself is a technique that allows devices to recognize and understand the sounds we produce.
\end{abstract}

Keywords: Game FPS, Speech Recognition 


\section{Pendahuluan}

Seiring dengan perkembangan permainan atau game yang persaingannya sangat ketat didalam dunia Teknologi,Konsumen sering dihadapkan pada permainan yang memiliki beberapa kategori atau Genre,diantaranya adalah Genre FPS ( First Person Shooter) (Armanda, 2020). Permainan fps ini memiliki keunikan tersendiri,dimana setiap permainan mempunyai latar cerita yang berbeda beda dan npc yang unik. NPC adalah sebuah subjek dalam Game yang tidak bisa dikendalikan oleh Pemain, tetapi dikendalian oleh program computer (Feng, 2008). Oleh sebab itu, agar dapat meningkatkan adrenalin, mengukur keberanian seseorang dan ketegangan yang sangat terasa jika di bandingkan dengan permainan bergenre lainnya. Apalagi dengan sekarang hadirnya Smartphone, bermain game FPS lebih mudah dan bisa dimainkan di mana saja. Tetapi, kebanyakan game FPS hanya mengandalkan kontrol manual seperti menggunakan mouse dan keyboard atau joystick.

Sebuah sensasi dalam dunia game FPS, yaitu mengimplementasikan Speech Recognition atau pengenalan ucapan kedalam game FPS tersebut akan dimunculkan. Metode Speech recognition atau pengenalan ucapan merupakan teknologi yang mampu mengenali ucapan atau perkataan tanpa memperdulikan siapa pembicaranya, masukan berupa suara mampu diubah menjadi text yang mampu dibaca oleh sistem (Al-Ghifari, 2020). Dengan menggunakan teknologi seperti ini pengguna bisa dengan leluasa memerintah hanya dengan menggunakan suara. Keunikan dari impelemntasi speech recognition pada game FPS sendiri adalah pemain dapat mengkontrol tokoh yang sedang dijalankan menggunakan suara.

Android telah menjadi sistem operasi terbesar didunia yang banyak diminati oleh pengguna dikarenakan kelebihan dari fitur fitur android yang dapat menjalankan mobile game dengan lancar, serta Smartphone Android dapat dimiliki dari berbagai kalangan dari kalangan kebawah sampai kalangan keatas (Feng, 2008). Kemajuan teknologi yang cepat memiliki dampak kuat pada akademisi (Huda, 2016). Mobile game merupakan jenis game yang dibuat khusus agar dapat berjalan pada perangkat mobile device seperti Apple, Android serta Windows Phone. Feng menyatakan bahwa "permainan game akan memberikan kenikmatan selama bermain game" (Munandar, 2014).

Permainan ini akan berfokus pada pengembangan navigasi karakter dengan menggunakan perintah suara. Tujuan penulis membuat game ini adalah untuk 
mengembangkan game FPS yang sudah ada agar terlihat lebih menarik dengan menggunakan metode Speech Recognition. Speech Recognition merupakan sebuah sistem yang memiliki kemampuan memahami ucapan manusia dalam penelitian ini (Shibly, 2016). Hal tersebut diharapkan dapat membantu memperkenalkan Indonesia ke ranah Internasional dan juga turut serta mengikuti perkembangan teknologi \& Industri 4.0

\section{Pembahasan}

\section{Pengertian Game}

Game berasal dari Bahasa Inggris yang berarti permainan, atau bisa diartikan sebagai aktifitas terstruktur yang difungsikan untuk bersenang senang. Game adalah suatu software dimana satu atau lebih pemain mengambil keputusan melalui control pada objek didalam game untuk suatu tujuan tertentu (Huda, 2016).

Permainan terdiri atas beberapa peraturan yang membangun situasi bersaing dari beberapa orang atau kelompok dengan memilih strategi yang digunakan untuk memaksimalkan kemenangan sendiri atau kelompok. Peraturan ini menentukan kemungkinan tindakan pada setiap pemain, sejumlah keterangan pemain diterima sebagai kemajuan, dan sejumlah kemenangan atau kekalahan dalam berbagai situasi (Backlund, 2013).

\section{First Person Shooter (FPS)}

First Player Shooter merupakan permainan sebuah permainan yang menunjukan konten kekerasan tinggi,dimana terdapat aksi tembak menembak,memukul dan juga menusuk orang,tergantung cerita dan tokoh didalam permainan tersebut. Pada permainan ini dibagi menjadi 2 mode yaitu TPS ( Third-Person Shooter) dan FPS (First-Person Shooter).perbedaannya ada pada view kita dalam bermain, dimana TPS memperlihatkan karakter yang sedang kita jalankan sedangkan FPS hanya memperlihatkan sebagian karakter yang sedang kita jalankan ( biasanya hanya memperlihatkan tangan ).

\section{Speech Recognition}

Speech Recognition merupakan salah satu dari bentuk AI (Artificial Intelligence). Speech Recognition adalah sebuah Teknik yang memungkinkan 
perangkat untuk mengenali dan memahami suara yang kita hasilkan. Kata yang muncul pada suara kita akan diolah dan dirubah menjadi sebuah format yang dapat dibaca oleh mesin atau aplikasi tersebut. Setelah kata dan frasa telah di olah menjadi format yang dapat dibaca oleh mesin atau aplikasi tersebut, speech recognition akan menganalisa perintah apa yang masuk dan pekerjaan atau respon apa yang harus di keluarkan oleh mesin atau aplikasi tersebut.

Dalam praktiknya, speech recognition akan membutuhkan sampel kata atau frasa yang di dapat dari ucapan para pengguna. Sampel dari kata dan frasa tersebut akan di rubah ke format khusus dan disimpan untuk digunakan sebagai landasan dalam respon selanjutnya.

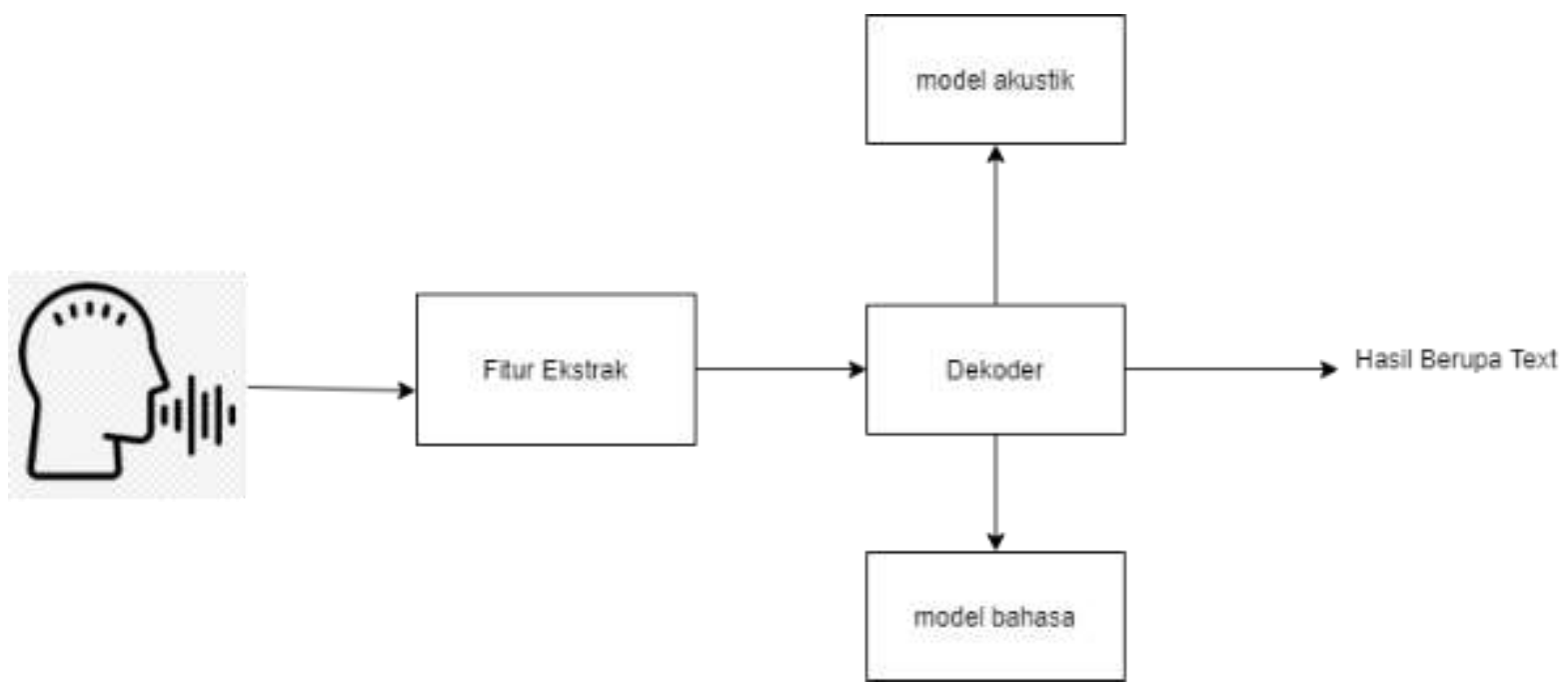

Gambar 1 Cara kerja Speech recognition

\section{Cara Kerja Speech Recognition}

Gambar diatas menggambarkan diagram blok sistem pengenalan ucapan sederhana. Seperti yang ditunjukkan pengguna berbicara yang disimpan dan diterjemahkan ke teks berdasarkan akustik, model bahasa dan jenis kelamin.

- Pengenalan ucapan pertama-tama mendeteksi dan menangkap kata-kata yang diucapkan.

- Mengkonversi ini menjadi representasi digital setelah penghapusan kebisingan. Ini dilakukan dengan menggunakan algoritma DSP.

- Memecah suara menjadi potongan yang lebih kecil jika memiliki pola yang sangat besar. 
- Sekarang pidato ditugaskan dengan fonem tertentu berdasarkan catatan dalam database dan berdasarkan probabilitas

\section{Perancangan Game}

Game ini menceritakan pasukan tantara Bersama dengan kelompoknya yang sedang menjalakan misi menjinakan bom yang terletak di sebuah Rumah yang ada di Indonesia. Didalam Rumah tersebut terdapat banyak teroris yang menjaga bom agar tidak dijinakan. Pada awal sebelum memulai permainan. Pemain dapat memilih senjata yang ingin diambil dan equipment yang ingin dibawa seperti granat, flashbang, smoke, decoy.

Awal permainan pemain berada di luar Rumah beserta kelompoknya. Ketika ingin memasuki rumah,musuh melempar granat dan melukai semua temannya sehingga pemain harus masuk sendirian di dalam rumah untuk menjinakan bom. Sebelum memasuki rumah,pemain harus melakukan Latihan terlebih dahulu agar dapat memainkannya dengan lancar. Dengan menggunakan suara untuk menggerakan karakter dan tombol yang tersedia di layar smartphone untuk menembak musuh. Permainan selesai Ketika pemain selamat dan dapat menjinakan bom yang ada di rumah tersebut. Ketika game telah selesai maka pemain akan diarahkan kearah menu.

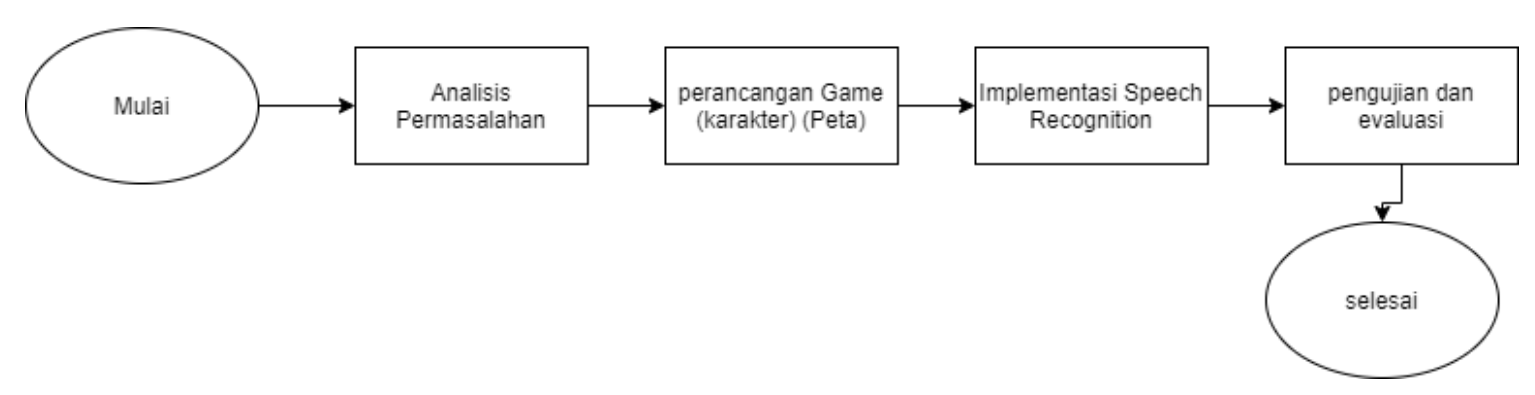

Gambar 2 Diagram alur penelitian 


\section{Desain Game}

Rancangan Karakter

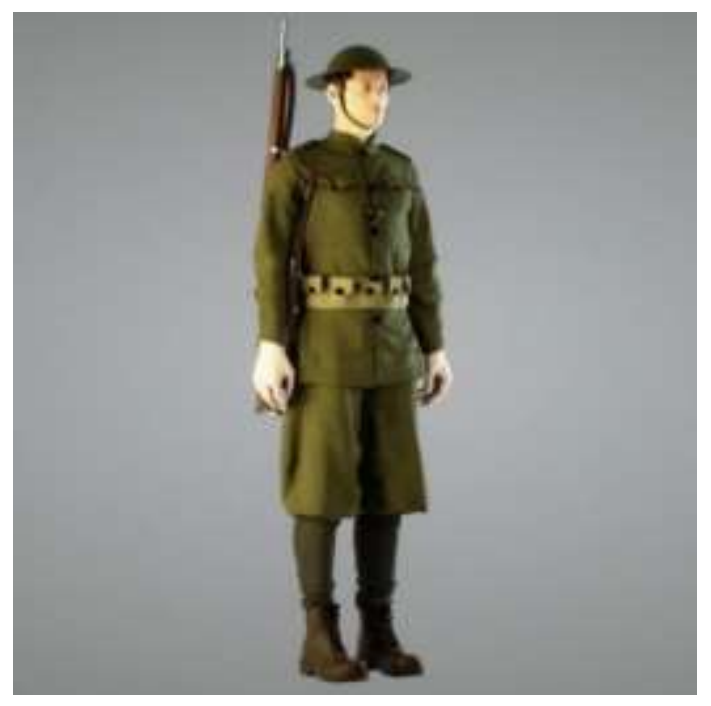

Gambar 3 Rancangan Karakter player

Gambar diatas merupakan rancangan karakter player yang akan dibuat,Karakter tersebut mereferensikan tentara Indonesia pada jaman dahulu. Dibuat menggunakan aplikasi Blender.

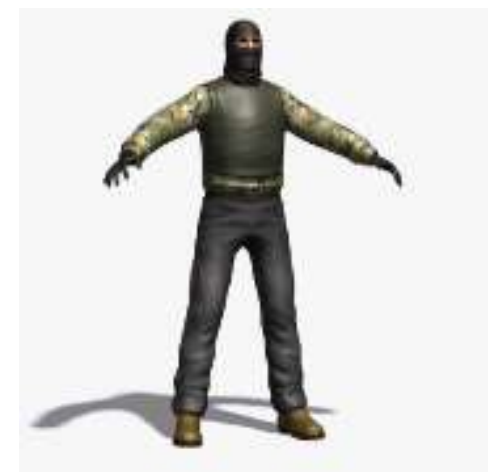

Gambar 4 Rancangan Karakter Musuh (NPC)

Gambar diatas merupakan rancangan karakter non playable character yang akan dibuat dengan aplikasi Blender.

\section{Rancangan map Game}

Peta yang dibuat di pada game ini dibangun menyerupai lokasi aslinya yang berada di Surabaya. Didalam rumah tersebut juga hampir sama persis seperti aslinya, perbedaannya terletak pada bagian desain luar diganti agar tidak menyalahi aturan hak cipta. Teroris akan ditempatkan di titik titik berbeda pada setiap lantai agar permainan tetap seru dan dapat diselesaikan dengan mudah. 


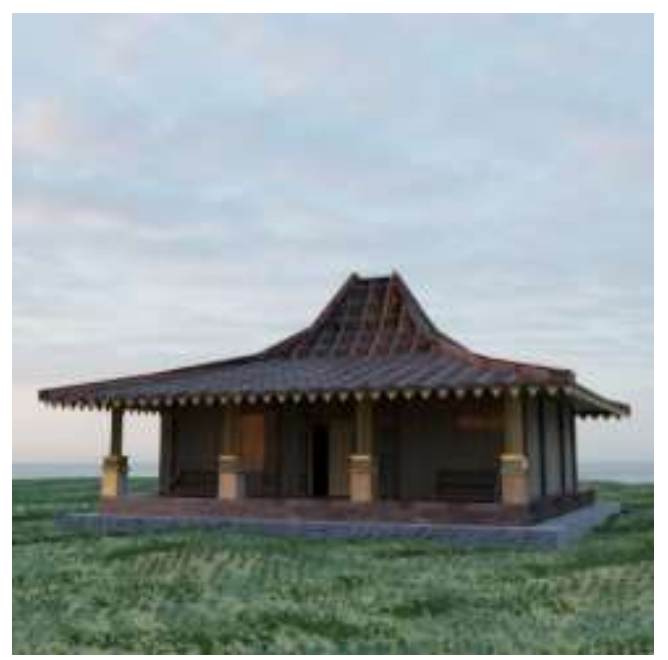

Gambar 5 rancangan map game

\section{Perancangan Speech Recognition}

Pada game ini menggunakan speech recognition yang berfungsi untuk menjalankan karakter yang sedang dimainkan. Dengan berbicara sesuai perintah yang diberikan pada petunjuk maka karakter akan mengikuti arahan dari pemain sesuai yang dibicarakan. Ada beberapa perintah yang tersedia untuk membantu pemain dalam memainkan game ini,berikut adalah table perintah yang tersedia.

\begin{tabular}{|c|c|c|}
\hline No & Nama Perintah & Keterangan \\
\hline 1 & Start the game & Memulai permainan \\
\hline 2 & Enable Walk & Karakter akan berjalan \\
\hline 3 & Turn left & $\begin{array}{l}\text { Karakter akan berbelok } \\
\text { ke kiri }\end{array}$ \\
\hline 4 & Turn right & $\begin{array}{l}\text { Karakter akan berbelok } \\
\text { ke kanan }\end{array}$ \\
\hline 5 & Enable sprint & $\begin{array}{l}\text { Karakter akan } \\
\text { melompat }\end{array}$ \\
\hline 6 & Stop movement & Karakter akan berhenti \\
\hline 7 & One eighty & $\begin{array}{l}\text { Karakter akan berputar } \\
180^{\circ}\end{array}$ \\
\hline
\end{tabular}

Tabel 1 Perintah Speech Recognition yang tersedia 
Berikut ini adalah diagram alur speech recognition:

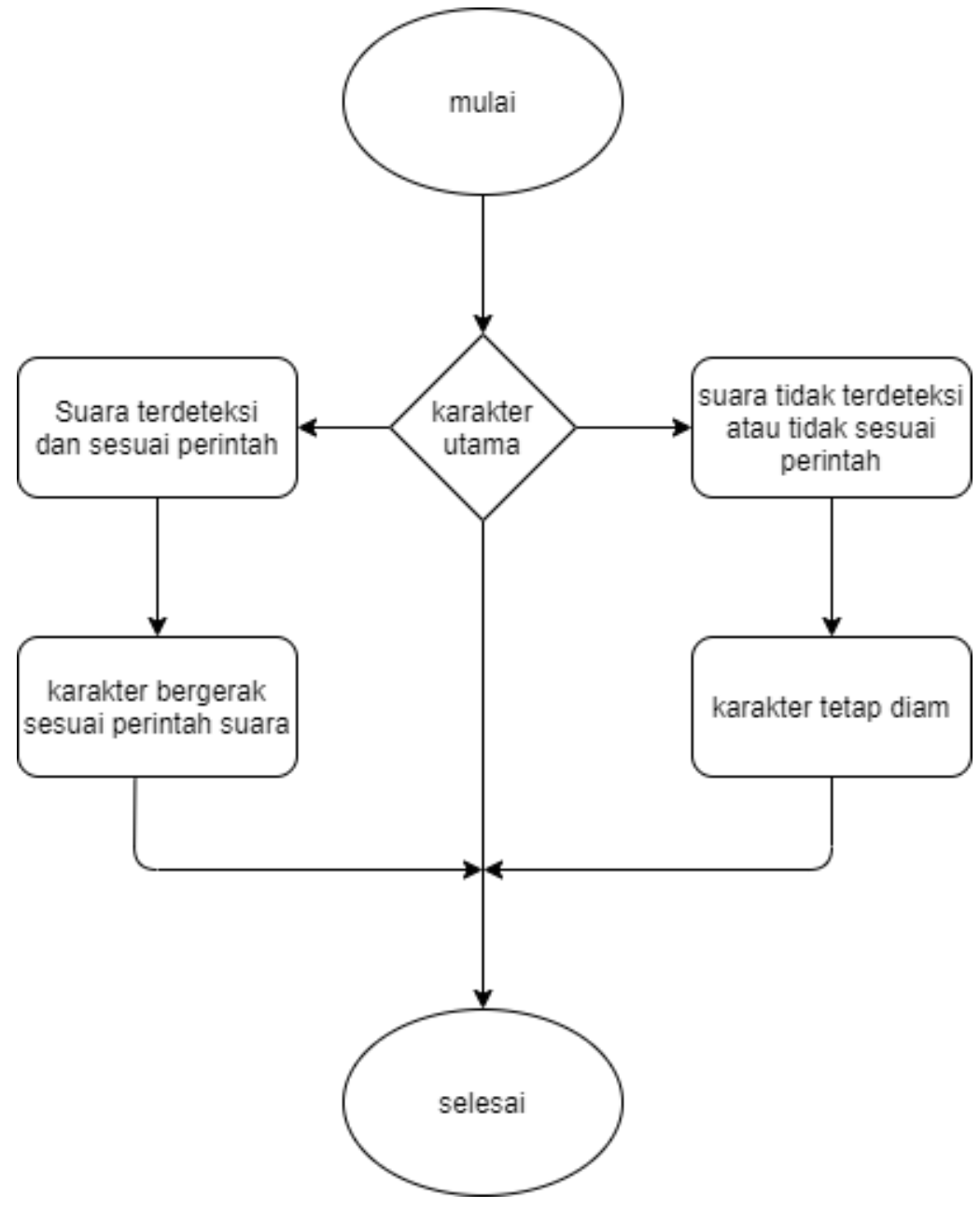

Gambar 6 Diagram alir speech Recognition

\section{Analisis Permasalahan dan kebutuhan sistem}

Pada saat perancangan game ini ada beberapa hal yang perlu diperhatikan dimana Speech Recognition yang dipakai pada karakter utama akan bekerja Ketika pemain mengucapkan kata yang sudah tersedia pada game tersebut. Pembuatan Speech Recognition ini memanfaatkan fitur pemograman yang ada pada Unreal Engine 4 dalam UE C\# dan plugin google Speech to Text yang tersedia di github

Seperti yang dijelaskan sebelumnya,penelitian ini menggunakan Engine dari Unreal Engine untuk membuat game tersebut. Unreal Engine memerlukan spesifikasi perangkat keras seperti pada tabel 3.4.1 agar dapat berjalan dengan lancar. 


\begin{tabular}{cc}
\hline $\begin{array}{c}\text { Operating } \\
\text { System }\end{array}$ & Windows 10 64-bit \\
\hline Processor & $\begin{array}{c}\text { Quad-core Intel or } \\
\text { AMD, 2.5 GHz or } \\
\text { faster }\end{array}$ \\
\hline Memory & 8 GB RAM \\
\hline $\begin{array}{c}\text { Video } \\
\text { Card/Direct } \\
\text { X Version }\end{array}$ & $\begin{array}{c}\text { DirectX 11 or DirectX } \\
12 \text { compatible } \\
\text { graphics card }\end{array}$ \\
\hline
\end{tabular}

Tabel 2 kebutuhan sistem

\section{Implementasi Sistem}

Pada tahap implementasi sistem, pengujian yang diberikan adalah berupa pengecekan Speech Recognition yang dimasukan pada karakter utama. Setelah itu penulis akan melakukan running pada game tersebut guna melakukan pengecekan kemampuan Speech Recognition yang ada pada Karakter Utama. Berikut ini adalah diagram alur game

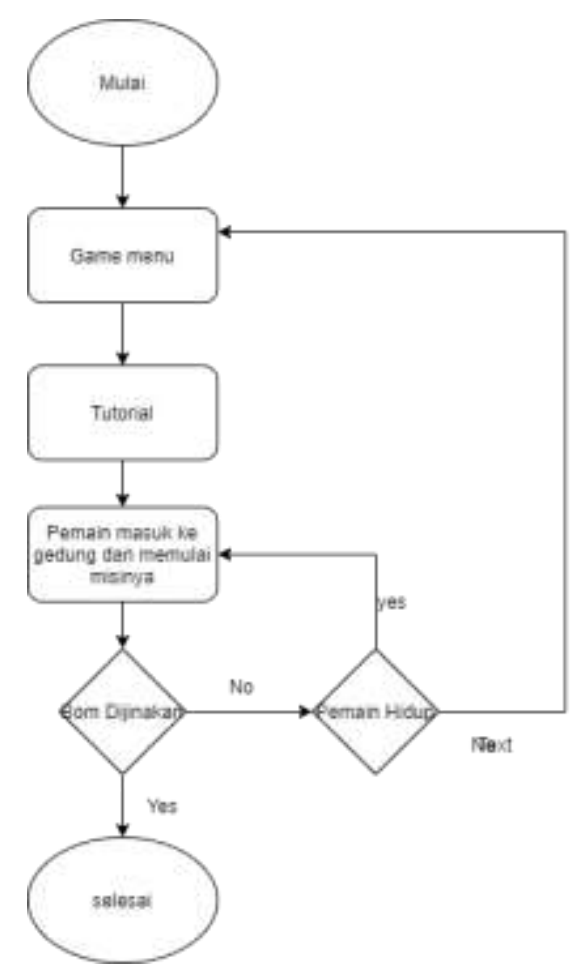

Gambar 7 Diagram alur game 
Penerapan yang ada pada logic musuh pada mulanya musuh akan berpatroli memutari lokasi,Ketika musuh mendeteksi pemain maka langsung menembak pemain,Ketika Health Point musuh berkurang setengah musuh akan mencari perlindungan untuk meregerenasi Health Point. Ketika Pemain mati musuh akan melanjutkan berpatroli lagi.

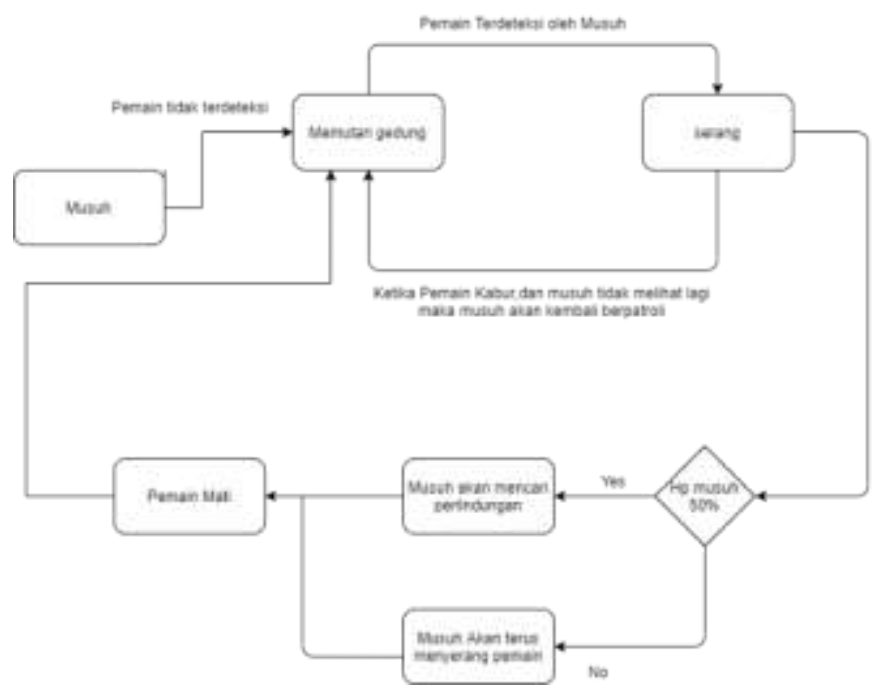

Gambar 8 Diagram logic NPC

\section{Hasil dan Pembahasan}

Pengujian respon karakter utama dengan menggunakan Speech recognition dilakukan dengan cara pemain mengucapkan kata yang sesuai dengan perintah yang telah tersedia,jika suara terdeteksi dan sesuai perintah maka karakter akan berpindah sesuai dengan perintah.

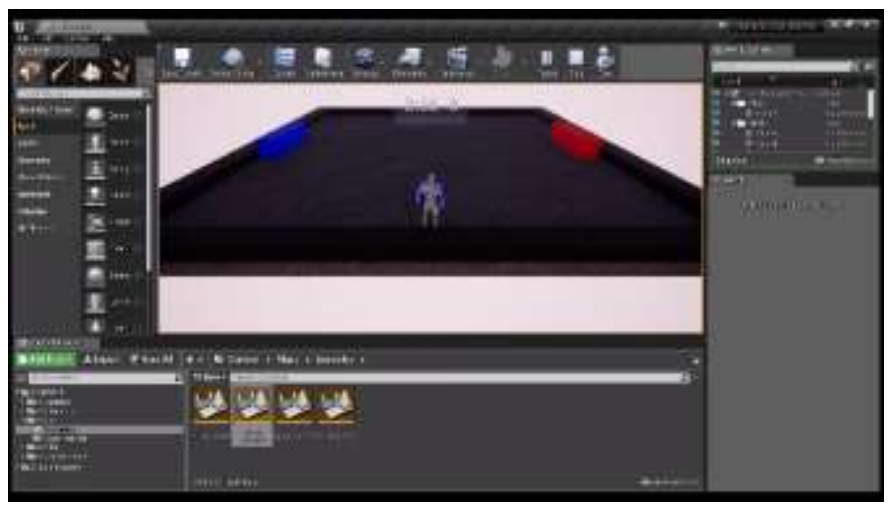

Gambar 9 Karakter diam Ketika belum mendapatkan perintah 


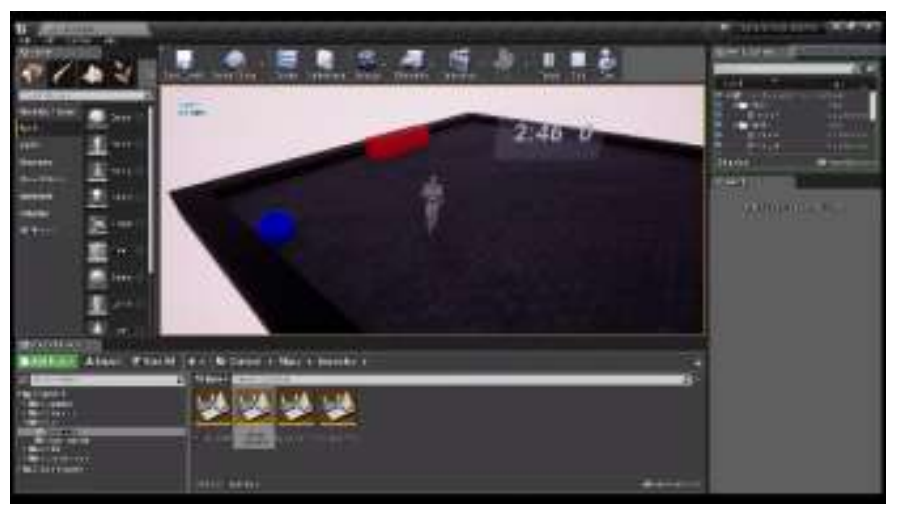

Gambar 10 karakter akan berjalan sesuai dengan perintah

Ketika pemain memberi perintah melalui suara dan perintah tersebut valid dan sesuai dengan yang ada didalam game,maka karakter akan bergerak sesuai perintah tersebut. Jika perintah atau suara tidak ditemukan maka karakter akan tetap berada dalam posisinya.

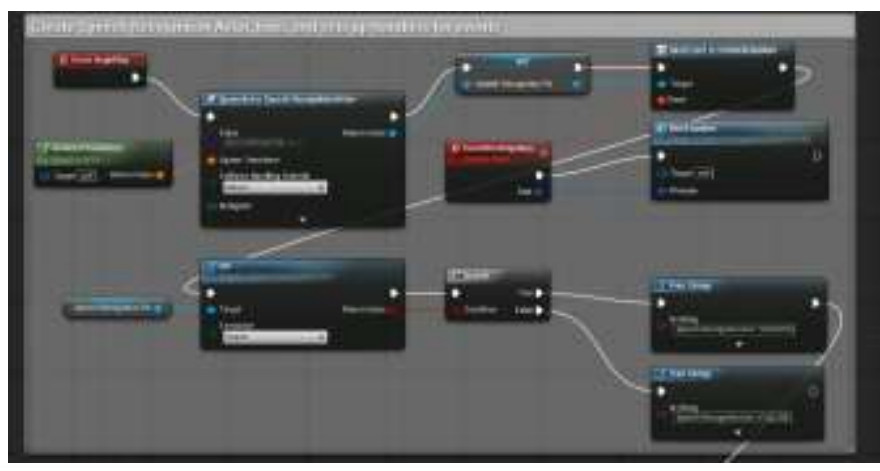

Gambar 12 Blueprint implementasi speech recognition kedalam karakter utama

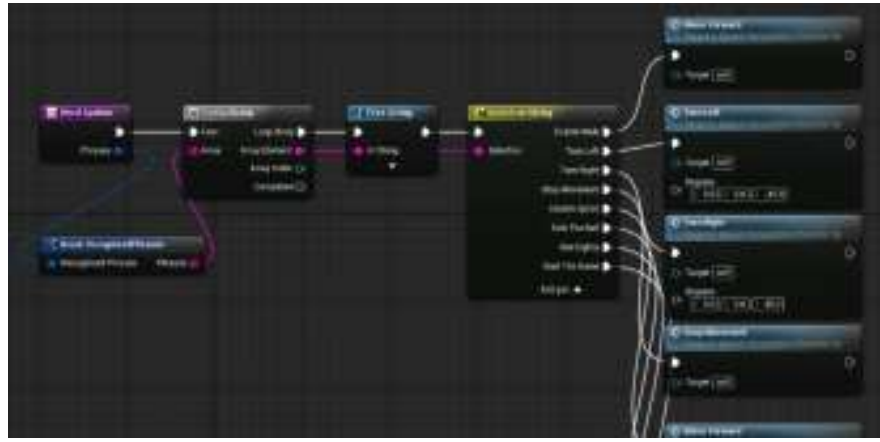

Gambar 13 Blueprint Implementasi perintah yang dimasukan ke dalam karakter

Pada Gambar 13, Karakter akan bergerak sesuai perintah yang ada pada blueprint switch on String seperti Enable Walk, Turn Left, Turn Right, Stop Movement dan sebagainya. 


\section{Kesimpulan}

Dengan menggunakan unreal engine untuk membuat game tersebut, implementasi speech recognition pada sebuah game untuk mengkontrol karakter tersebut sangat dimungkinkan. Dengan adanya game ini diharapkan bisa meramaikan pasar industri game dan selanjutnya dapat membuat game game yang mengimplementasikan metode ini. Saran saya, kedepannya bisa dilakukan pengujian terhadap speech recognition itu sendiri agar dapat menggunakan Bahasa Indonesia.

\section{Referensi}

Al-Ghifari, M.H. \& Rizqi, M. (2020), “Game Portal Virtual Tugu Pahlawan Dengan Mobile Device Menggunakan Augmented Reality", Program Studi Sistem Komputer, Fakultas Ilmu Komputer, Universitas Narotama.

Armanda, A. F. \& Rizqi, M. (2020), “Game 3d Perjuangan Rakyat Surabaya Dalam Pertempuran 10 November 1945 Dengan Belanda Menggunakan Unreal Engine," Program Studi Sistem Komputer, Fakultas Ilmu Komputer, Universitas Narotama.

Backlund, P., \& Hendrix, M. (2013, September). Educational games-are they worth the effort? A literature survey of the effectiveness of serious games. In 2013 5th international conference on games and virtual worlds for serious applications (VS-GAMES) (pp. 1-8). IEEE.

Feng, X., Chan, S., Brzezinski, J., \& Nair, C.(2008), "Measuring enjoyment of computer game play", AMCIS.

Huda, A. S. (2016). Game edukasi cepat tepat dengan metode finite satate machine (FSM) pada telepon cerdas (Doctoral dissertation, Universitas Islam Negeri Maulana Malik Ibrahim).

Munandar, B. (2014). Rancang Bangun Aplikasi Pelatihan Psikotes Berbasis Android (Doctoral dissertation, Universitas Muhammadiyah Surakarta).

Setiawan, W.P.A., Gumelar, A.B., Rizqi, M., Putra, F. D. C., Romadhonny, R. A., Nugroho, R. D. (2019), "Development of First-Person Shooting Games Using Human Voice Command and its Potential Use for Serious Game Engines", Program Studi Sistem Komputer, Fakultas Ilmu Komputer, Universitas Narotama.

Shibly, FHA. Lecturer in IT(2016), "Android Operating System: Architecture, Security Challenges and Solutions", South Eastern University of Sri Lanka, Oluvil, Sri Lanka. 